\title{
AN INCOMPLETE CONTRACT PERSPECTIVE ON PUBLIC GOOD PROVISION
}

\author{
David Martimort \\ University of Toulouse (IDEI-GREMAQ) and IUF, CEPR
}

\author{
Philippe De Donder and Etienne Billette de Villemeur \\ University of Toulouse (IDEI-GREMAQ)
}

\begin{abstract}
This paper surveys what can be learned from recent advances in the incomplete contract literature to understand how public goods are or should be provided. The paper starts with a section on the full information case that presents and discusses the classical Samuelson condition on the optimal provision of public goods. The rest of the paper presents results under asymmetric information. It is constituted of two main parts. In the first one, the social planner has complete contracting ability. We discuss the basic setting and assumptions of this comprehensive contracting approach and study the trade-offs it generates. The second part of the paper is devoted to the study of contracting incompleteness. Such incompleteness can emerge from various sources, which we present and discuss. We then study the case of a politically chosen decision-maker and the consequences of its inability to commit for more than one period and of the ability for individuals to form groups. Finally, we address the problem of the choice between public and private forms of public good provision. The concluding section summarizes the main policy lessons.
\end{abstract}

Keywords. Asymmetric information; Incomplete contracts; Public goods

\section{Introduction}

This paper is primarily concerned with public goods. In their purest form, these goods share two properties: nonrivalry and nonexcludability. The first property means that it does not cost anything for an additional individual to enjoy the benefits of the good. The second relates to the fact that it is difficult or impossible to exclude individuals from the enjoyment of the public good. Prime examples of public goods are national defence or lighthouses: the cost of a lighthouse does not depend on the number of ships that sail past it, and it is impossible to prevent any ship going past from the navigational benefits of the lighthouse. 
The main problem with public goods is that either they will not be supplied by the market or, if supplied, will be supplied in insufficient quantity. This is mainly because of the nonexcludability of those goods: because private entrepreneurs cannot make sure that only paying consumers will access their goods, they will underprovide (or even not provide at all) these kinds of goods. The market underprovision of public goods provides a rationale for many government activities.

This paper surveys what can be learned from recent advances in the incomplete contract literature to understand how public goods (or more generally, goods that share at least one characteristic of a public good or goods associated with a market failure) are or should be provided. The paper starts with a section on the full information case and states the classical Samuelson condition on the optimal provision of public goods when the benevolent public good provider knows all relevant information on both the cost of provision and the willingness to pay by consumers. This section also contains a presentation and discussion of the assumptions under which the Samuelson result holds.

The rest of the paper presents results under asymmetric information, i.e. when the social planner does not have all relevant information. It is constituted of two main parts. In the first one, the social planner has complete contracting ability. That is, it can contract on anything that is observable in the economy, including the public good level. Furthermore, it is benevolent and has the ability to commit to a public good policy even if this policy extends over many periods. These assumptions constitute the framework of the comprehensive contracting approach, which is studied in section 3. We first discuss the basic setting and assumptions of this approach in section 3.1. We then present the trade-offs that we are facing on the demand side of the economy (section 3.2) and on the supply side (section 3.3).

Section 4 is devoted to the study of contracting incompleteness. Such incompleteness can emerge from various sources, which we first present and discuss. We study in section 4.1 the situation that arises when the decision-maker is chosen out of a political process. This situation gives rise to both static and dynamic inefficiencies that we study in turn. A related problem comes from the inability of the decision-maker to commit for more than one period. We discuss in section 4.2 the problems posed by this inability, such as ratchet-effects, hold-up situations and renegotiations. Section 4.3 analyses what happens when individuals can form groups in order to pursue their own objectives rather than the decision-maker's. Problems then arise both on the demand and the supply sides, with phenomena like capture of regulators. Finally, we address the problem of the choice between public and private forms of public good provision in section 4.4. We first show that this problem can only be addressed in an incomplete contract setting. We then study privatization as a commitment device, compare the incentives in the private and public sector and mention the trade-off between cost reduction and quality innovation in both sectors.

The concluding section summarizes the main policy lessons to be derived from the incomplete contract approach to public good provisions.

\footnotetext{
(C) Blackwell Publishing Ltd. 2005
} 


\section{The Full Information Case}

The basic textbook principle used to understand how much public good should be supplied was offered in a seminal paper by Samuelson (1954). In his view, the optimal amount $x^{F B}$ of public good should balance the marginal cost of producing it with the sum of marginal benefits that it yields over the whole society.

Let us be more formal and consider a society made of $N$ agents with respective utility functions $U_{i}=\theta_{i} v(x)-t_{i}, i \in\{1, \ldots, n\}$, where $\theta_{i}$ is a scaling preference parameter multiplying the benefit $v(x)$ from consuming $x$ units of the public good and $t_{i}$ is the monetary contribution of agent $i$ to its financing. Suppose also that supplying the public good costs $\beta C(x)$ to society (where $\beta$ is some scale parameter) and that this cost is covered by the sum of individual contributions. Then, assuming the concavity of $v(\bullet)$ and the convexity of $C(\bullet)$, it can be shown that the first-best amount of public good satisfies the so-called Samuelson condition:

$$
\left(\sum_{i=1}^{n} \theta_{i}\right) v^{\prime}\left(x^{F B}\right)=\beta C^{\prime}\left(x^{F B}\right),
$$

where the left-hand side represents the sum of the marginal willingnesses to pay for the public good, and the right-hand side is the marginal cost of production of the good. Remark that the nonrivalry between consumers explains why the Samuelson condition adds the individual willingnesses to pay for the good. ${ }^{1}$

For a large population where tastes are distributed with a cumulative distribution $\mathrm{F}(\bullet)$ on $[0,+\infty]$ (with density $\mathrm{f}=\mathrm{F}^{\prime}$ ), the previous condition can be rewritten as

$$
\left(\int_{0}^{\infty} \theta f(\theta) d \theta\right) v^{\prime}\left(x^{F B}\right)=\beta C^{\prime}\left(x^{F B}\right)
$$

or if tastes are normalized so that the average taste parameter over the entire society is one, $\int_{0}^{\infty} \theta f(\theta) d \theta=1$,

$$
v^{\prime}\left(x^{F B}\right)=\beta C^{\prime}\left(x^{F B}\right) .
$$

The Samuelson condition above characterizes a first-best or efficient allocation of resources in the economy. Furthermore, it is worth noting that in this environment with quasi-linear utilities ${ }^{2}$ and perfect information, there is no conflict between efficiency and redistributive concerns. In other terms, it is always possible to find a compensation scheme that makes everyone better off with this optimal quantity of public good than with no public good at all. This also means that the initial allocation of rights across agents and the productive sector of the economy is irrelevant, because the social planner can guarantee to everyone to be better off with the optimal public good quantity. This is an instance where the celebrated 'Coase Theorem' applies.

Consider the following example. A local community must decide whether a polluting firm should produce or not. The public good here is thus the air's quality. Whether the firm has initial right to pollute or whether the agents have initial rights for not being polluted (may be because the firm was not here in the previous 
period) does not matter. In both cases, the same amount of pollution is allowed and whatever group benefits more from this level compensates the other.

It should also be stressed that the distribution of tastes in the population affects the optimal amount of public good only through its expectation. The exact shape of the distribution plays no further role. In other words, it is sufficient for the social planner to know the average benefits derived from the public good (in addition to the production costs) for computing the optimal amount $x^{F B}$.

Of course, the Samuelsonian framework is based on a number of assumptions, which we state and discuss before relaxing them:

- Complete information: The Samuelsonian approach presumes that the social planner has all relevant information to compute the optimal allocation. This involves, of course, information on tastes: not only the overall distribution of tastes but also the individual tastes of every single agent in society are known by the planner. Indeed, while the optimal allocation is fully characterized by the average benefits derived from the consumption of the public good, the implementation of the allocation, i.e. the computation of transfers requires the knowledge of the benefits for each single individual. Clearly, in reality, the planner is likely to have only some prior knowledge on this distribution.

Also, the planner is assumed to know all relevant technological parameters necessary to learn the cost function of the productive sector. In formula (2) this means, for instance, that the scale parameter $\beta$ is common knowledge. In reality, the planner may only have imperfect knowledge of this parameter. The planner may, for instance, know only that $\beta$ is distributed over some interval $[\beta, \bar{\beta}]$ with a cumulative distribution $G(\bullet)$ (density $g=G^{\prime}$ ).

Asymmetric information either on the demand or the supply sides of the economy puts constraints on the set of feasible allocations, where an allocation is a pair consisting of an amount of public good and of a distribution of the induced individuals' utilities.

An important question that we tackle in the rest of this survey is how asymmetric information restores a role for the allocation of rights in the economy.

- Mediated bargaining: In the Samuelsonian framework, the benevolent planner organizes the production of the public good and collects the individual contributions. Appealing to this mediator to organize the economy is supposed to be costless. The implicit role of mediator is to avoid the free-riding problem in collective action stressed by Olson (1965). The mediator is a perfect representative of all agents in society and maximizes the sum of their utilities, which is the relevant welfare criterion with our assumed quasi-linear utility functions.

Of course, relaxing this assumption opens up the possibility that the planner himself is a player of the game with his own objectives (may be aligned with those of subgroups of society or with the productive sector if the decision-maker is captured). Politics then may matter, because it consists in choosing the representative in charge of building the public good mechanism. As soon as 
politics matters, the design of political rights of the various agents plays a role in determining the size and composition of the public goods provided.

- Transaction Costs: Those are the costs involved in the writing, enforcement and renegotiation of contracts with the productive sectors, or in the delegation of contracting to this productive sector. There is no unified theoretical framework to describe those costs. However, there is a common theme of the literature which is that property rights (defined in a broad sense) affect those costs and, thus the optimal amount of public good provided.

In what follows, we relax the assumption of complete information. The next section is devoted to the case of complete contracting in asymmetric information environments. Section 4 then proposes a general theoretical framework aimed at understanding how various contractual incompletenesses affect the allocation of resources in the economy. Within this framework, we can describe how various rights, whether on the political or on the ownership sides, affect efficiency and redistribution considerations.

\section{Asymmetric Information and Comprehensive Contracting}

\subsection{Setting and Assumptions}

Let us still consider, as Samuelson did, that the planner is a benevolent representative concerned with the well-being of all agents in society. However, from now on we relax the assumption of complete information. The Revelation Principle [Myerson (1979) and Laffont and Martimort (2002) among many others] states that there is no loss of generality in restricting the mediator to offer the so-called direct revelation mechanisms.

With such mechanisms, the mediator asks the individuals about their valuations and the firm, which produces the public good, about its production cost. According to those reports, the planner decides how much to produce and how much each individual should contribute to cover the production costs.

Such mechanisms, to be feasible, must satisfy a set of incentive compatibility constraints which simply ensure that reports are truthful.

To understand the force of incentive compatibility, one may consider the design of a public good mechanism as a two-step procedure. In the first step, the planner decides on the level of public good as a function of the cost reported by the supplier and as a function of the valuations reported by agents. Given this choice, the planner then chooses a set of taxes and transfers so that both sides of the economy find optimal to reveal the truth on their preferences. Incentive compatibility puts restrictions on the taxes imposed on agents and on the transfers to the productive sector.

These constraints depend on the implementation concept used. Two equilibrium concepts are of particular importance. First, agents may be Bayesian and compute their optimal truthful strategies taking rational expectations over those of the others. Another concept requires that agents find optimal to tell the truth

(C) Blackwell Publishing Ltd. 2005 
for any reports of the others. Truthful strategies are then said to be dominant This second implementation concept does not require agents to form beliefs over the tastes of others. It is thus less demanding in terms of the rationality of the agents composing the demand side of the economy.

An important question to which we come back soon is how these constraints conflict with other requirements such as

- Budget balance: The sum of taxes raised must cover the cost of producing the public good;

- Veto right: Producing the public good must ensure to agents at least their payoff without it, or more generally, what they get by expressing their rights.

Before giving the main results obtained within this framework in the literature, we briefly state a number of implicit assumptions behind the Revelation Principle above. We discuss more fully these assumptions in section 4 , because the failure to respect each of these assumptions gives rise to a particular form of contractual incompleteness.

- Unified view of the government: The government is assumed to be a single body with welfare maximization as its sole objective;

- Collusion: Behind the use of equilibrium concepts like Bayesian-Nash or dominant strategies equilibria, is the implicit assumption that collusive groups do not form to affect the allocation of resources. In a fully comprehensive contracting framework, the mediator can costlessly prevent the establishment of these collusive groups.

- Full verifiability: The comprehensive contracting paradigm assumes that the level of public good can be contracted upon, i.e. a Court of Justice can be used to verify its level.

In the next two subsections, we assume that these four assumptions hold, and we give theoretical foundations to (property and political) rights in this comprehensive grand-contracting approach.

\subsection{Demand Side Trade-offs: Efficiency versus Distribution}

We first show how the efficiency objective may conflict with basic rights, such as veto powers. We then study in section 3.2.2 a well-known consequence of this conflict for large economies, namely the free-riding problem. We discuss the possibility of designing property rights that allow for an efficient public good provision in section 3.2.3. Finally, we study second-best mechanisms and compare the first- and second-best quantities of public goods in section 3.2.4.

\subsubsection{The Scope for Efficiency}

Consider the benevolent uninformed mediator of the previous section and suppose that neither the individuals nor the firm have any rights whatsoever: they have to accept the mechanism for public good provision whatever the level of utility (or profit) they may get from it. It is well known, at least since Groves

(C) Blackwell Publishing Ltd. 2005 
(1973) that the first-best level of public good can be implemented in this context with the agents playing dominant strategies. The way to obtain this is to construct the individual tax paid by each agent so that it corresponds (up to a constant) to minus the aggregate payoff of all other agents. Then, each privately informed agent, when modifying his report, pays the externality that he exerts on others. As a result, his private objective becomes aligned with the social objective, and he fully internalizes the impact of his own report on the welfare of others. The right decision is then implemented.

Of course, these 'pay the externality' schedules may fail (and generically do so) to balance the budget. To avoid running a deficit requires to give up the excessively stringent implementation concept above and to rely instead on the weaker concept of Bayesian implementation.

In such a context, Arrow (1979) and d'Aspremont and Gérard-Varet, (1979) have shown that budget balance can be obtained under a large variety of informational contexts. The key is that the pay-the-externality payments found with dominant strategies can be averaged over the possible types of other agents to obtain the new payment schedule of a given agent in a Bayesian environment. This leaves one more degree of freedom, that can be used to satisfy budget balance, still keeping the first-best level of public good.

It was soon recognized by Laffont and Maskin (1979) that these mechanisms, even though they look attractive on normative grounds, may fail to guarantee a positive level of utility to all agents in society. Those who do not put enough value on the public good may receive a negative payoff just to prevent other agents with a greater valuation to underreport this valuation and thereby save on their tax payments.

When acceptance is not mandatory and must be induced, agents cannot get less than their reservation utility ${ }^{3}$ from playing the mechanism. The tax paid by agents who do not value much the good is thus limited by these participation constraints, and the incentives of agents with higher valuations to underestimate them and save on their tax payments are in general impossible to satisfy. ${ }^{4}$ For a benevolent social planner concerned with the maximization of the sum of agents' utilities in society, there exists a true conflict between achieving allocative efficiency under asymmetric information and guaranteeing a minimal level of welfare to those agents who are valuing less the public good.

The basic lesson here is thus that the mere existence of some basic rights, like veto power for the agents, may make impossible an efficient provision of the public good even if the State is run by a benevolent decision-maker. This result is a major achievement of incentive theory even though it is a quite negative one.

Lastly, it is worth noticing that there nevertheless exists a solution to the tradeoff between efficiency and redistribution even in large economies, but it is based on a violation of some political rights. This solution is based on a sampling mechanism and has been analysed by Green and Laffont (1979) and more recently Gary-Bobo and Jaaidane (2000). The idea here is for the benevolent decision maker to ask only a strict subset of agents for their types and to have them pay Groves transfers restricted to this subset. To obtain budget balance, the

(C) Blackwell Publishing Ltd. 2005 
deficit associated to these transfers is paid by other agents who do not have been asked for their types. If the sample is large enough, the decision-maker can, by the Strong Law of Large Numbers, approximate the average valuation from the sample and choose almost the first-best level of public good. The drawback of these mechanisms is that they do not give to everybody the same ex-post right to influence the decision. ${ }^{5}$

\subsubsection{Public Good in Large Economies and the Free-Riding Problem}

In fact, the trade-off between efficiency and respect of basic rights for agents gives some strong theoretical foundations to the well-observed free-riding problem in public good provision. This phenomenon is related to the nonexcludability of the public good. Agents are induced to underestimate their willingness to pay and to expect that others will support the burden of its financing. Of course, in equilibrium, everybody does so, and the amount of public good provided may be significantly lower than what would be socially optimal.

This problem can be illustrated with the papers by Rob (1989) and Mailath and Postlewaite (1990). These authors looked at a very specific public-good problem: a binary yes or no decision; for instance, whether a bridge of a given size should be built or not. All agents simultaneously announce the amount they are ready to pay for the financing of the project. The project is enacted only if the sum of those amounts is greater than the cost of the project. These papers study the case where agents have independent valuations for the use of the public good, and where the sum of the valuations is greater than the cost of the project, i.e. where efficiency recommends that the project be built. They nevertheless show that, when the per capita cost of the project exceeds the lowest possible valuation that agents may have, the probability of an affirmative efficient decision goes to zero. The intuition behind this result is straightforward. For a large population, an individual cannot really manipulate the decision to build, or not, the project by his individual report: no one is pivotal. However, at the same time, this individual wants to minimize his tax payment and does so by claiming the lowest possible valuation within the existing support. When all agents do so, the total amount raised does not cover the cost of public good by assumption and the project is not built.

\subsubsection{The Structure of Efficient Rights}

This last result leaves us with a quite negative view of the impact of giving rights to agents in a society. This insight is more general and, in fact, the success of a mechanism for public good provision depends crucially on the distribution of rights, i.e. on the participation constraints imposed on the mechanism by the possibility that agents use those rights. In particular, there may exist some allocations of rights which are less an obstacle to efficiency than the one seen above.

That efficiency may not always conflict with participation constraints in a world of asymmetric information was a point made earlier in private goods

(C) Blackwell Publishing Ltd. 2005 
environments by Samuelson (1985) and Cramton et al (1987). ${ }^{6}$ More precisely, the structure of property rights can be judiciously chosen so that efficiency can still be obtained even under asymmetric information.

Maybe more importantly, a large asymmetry among the rights of agents may be an obstacle to efficiency, as has been shown by Neeman (1999) in a publicgood framework. To see why, consider our earlier example: a polluting firm is located in a town inhabited by $n$ agents. The firm's profit increases with the amount of pollution, whereas the residents' welfare diminishes accordingly. The firm has private information on its profitability, the agents have private information on their benefits of enjoying a clean environment. The structure of property rights specifies how much pollution the firm is allowed to emit. Observe that the socially efficient amount of pollution, as given by the Samuelson condition, does not depend on the allocation of rights, because it balances the aggregate cost (in individuals' welfare terms) of pollution against its benefit (in profitability terms). The structure of rights nevertheless has a tremendous importance on the allocation that will be reached in this setting, as we now show.

Suppose first that all rights are left to the firm and that all individuals can simultaneously transfer money to the firm in exchange for lower pollution levels. We are then back to the Mailath and Postlewaite (1990) framework seen above, with strong incentives for individuals to underestimate their aversion to pollution, in hope that others will pay to rein in the firm. As a result, the firm will produce too much pollution from a social welfare viewpoint. On the other hand, suppose that the firm has no right to pollute whatsoever. Then, agents may have an incentive to overstate their aversion to pollution to get a higher compensation in exchange of some pollution. The mechanism in this case is similar to the previous one: because no individual alone is pivotal, each tries to maximize the net payment he receives and the economy ends up with, in this case, too little pollution.

Those two polar cases show that there may exist some intermediate level of rights, which ensures that the efficient level of pollution is attained. This structure of property rights may, of course, be highly sensitive to the technological parameters and to the preferences for clean air. Neeman (1999) nevertheless provides robust bounds on those rights so that efficiency is obtained under many circumstances.

\subsubsection{Second-Best Policies}

When there does not exist a structure of property rights, which ensures efficiency, two alternative paths can be taken. On the one hand, one can follow Neeman (1999) and define the degree of coercion of a mechanism, roughly speaking, the extent to which the participation constraint of an agent must be violated to maintain efficiency. It turns out that in large economies this degree is bounded, suggesting that only small deviations from voluntary bargaining are needed.

On the other hand, one can give up efficiency and look for the optimal mechanism that satisfies the participation constraints of all agents, a secondbest mechanism. ${ }^{7}$ Let us consider, as an example, the simple case where agents can guarantee themselves a reservation utility of zero by vetoing the mechanism, 
in which case the public good is not provided. The discussion above has already shown that there may be a conflict between efficiency and the veto right of all agents in the economy. To solve this conflict, the benevolent decision-maker is forced to reduce the size of the public good provided, or if it is a binary decision, to cancel its production even when it would be socially efficient.

Without diving into the full technicalities of these analysis, it is worth comparing the formulae giving the amount of public good provided in the case of a continuum of agents under symmetric (equation 2) and asymmetric information. Let us first imagine that the cost of the public good is small with respect to all public spending. Its impact on the value of the public funds, denoted thereafter by $\lambda$, can thus be neglected. ${ }^{8}$

With asymmetric information, the incentives of agents to underreport their willingness to pay for the good can be captured by replacing their true valuation $\theta$ by a lower virtual valuation $\tilde{\theta}(\theta)$, with

$$
\tilde{\theta}(\theta)=\theta-\frac{\lambda}{1+\lambda}\left(\frac{1-F(\theta)}{f(\theta)}\right)<\theta .
$$

Indeed, because of asymmetric information, each agent (except that with the lowest valuation) gets an information rent from his ability to pretend having a lower valuation than what he really has. This temptation to lie increases with the public good level. Incentives for lying and thus the agents' information rents are reduced by distorting downwards the level of public good. Everything happens thus as if agents had a lower valuation than what they really have.

The second-best rule now trades off the sum of the virtual marginal benefits of providing the public good against its marginal cost. This yields the second-best Samuelson Conditions found, for instance, in Laffont and Martimort (1999a). In our context, with a continuum of agents drawn on $[0,+\infty]$, we get the value $x^{S B}$ as a solution to:

$$
\left(\int_{0}^{\infty} f(\theta) \tilde{\theta} d \theta\right) v^{\prime}\left(x^{S B}\right)=C^{\prime}\left(x^{S B}\right) .
$$

Integrating, we get $\int_{0}^{\infty} f(\theta) \tilde{\theta}(\theta) d \theta=1-(\lambda /(1+\lambda)) \int_{0}^{\infty}(1-F(\theta)) d \theta=1 /(1+\lambda)$.

Hence, we finally obtain

$$
\frac{v^{\prime}\left(x^{S B}\right)}{1+\lambda}=\beta C^{\prime}\left(x^{S B}\right) .
$$

When the population is made of a continuum of agents and the cost of public funds is exogenously given, the second-best rule discounts the benefit for society as a whole, as can be seen by comparing (2) and (5). As the cost of public funds increases, this discount becomes more important and less public good is offered.

For large public goods like education, defense or health, the value of $\lambda$ can no longer be taken as constant and must be endogenized. The Mailath and Postlewaite (1990) result suggests then that the left-hand side of (5) goes to zero under mild assumptions ${ }^{9}$, meaning that no public good is ever produced! 


\subsection{Supply-Side Trade-Offs: Efficiency versus Rent Extraction}

Let us now turn to the supply side. We first explain the trade-off between efficiency and informational rent in asymmetric information models, before discussing the role of ex ante and ex post (or yardstick) competition.

\subsubsection{Efficiency and the informational Rent}

The benevolent decision-maker may face a trade-off between looking for an efficient (cost-minimizing) allocation and extracting the informational rent of the firm privately informed about its costs. This basic point has been developed at length in the regulation literature. ${ }^{10}$ It is not our purpose here to remind the main insights of this literature. However, proceeding as before in the case of asymmetric information on the demand side, we briefly explain the trade-off between efficiency and rent extraction found in the case of asymmetric information on the production technology.

First, note that an incentive mechanism must now request the firm to announce its cost parameter to the decision-maker or, alternatively, to select within a menu of options that the latter has initially proposed. To induce participation by the least efficient firm, or let this firm at least break even, the mechanism must cover the large cost incurred in case the good is produced. This makes it very attractive for a more efficient firm to exaggerate its costs and grasp this large compensation.

This incentive constraint of the most efficient firm affects the decision on the size of the public good. Inducing truthful revelation can only be done by giving up an information rent to the most efficient firm and this rent is socially costly if there is a cost of public funds. Reducing this rent calls for some second-best policy. With respect to the first-best amount, a lower level of public good is supplied.

As for the demand side of the economy, everything happens as if the true cost parameter of the firm $\beta$ was replaced by a higher virtual cost parameter $\tilde{\beta}(\beta)$ given by:

$$
\tilde{\beta}(\beta)=\beta+\frac{\lambda}{1+\lambda}\left(\frac{G(\beta)}{g(\beta)}\right),
$$

where $\lambda$ still denotes the cost of public funds.

The optimal level of public $\operatorname{good} x^{S B}(\beta)$ is now given by

$$
v^{\prime}\left(x^{S B}(\beta)\right)=\left(\beta+\frac{\lambda}{1+\lambda}\left(\frac{G(\beta)}{g(\beta)}\right)\right) C^{\prime}\left(x^{S B}(\beta)\right) .
$$

Of course, a larger cost of public funds renders the firm's informational rent very costly and calls for a larger downwards distortion in the amount of public good supplied.

\subsubsection{Competition and the Trade-Off between Efficiency and Rent Extraction}

It should be noticed that the rent due to asymmetric information can be somewhat reduced if the planner can introduce ex ante competition among potential suppliers of the public good by auctioning off the right to contract with the

(C) Blackwell Publishing Ltd. 2005 
State. ${ }^{11}$ Of course, the fact that public goods are often produced with increasing returns to scale prevents most of the time ex post competition to be a valuable option for the planner. Ex ante competition amounts to a potential bidding procedure among applicants (potential suppliers) with the least-cost firm being selected. Even if the costs of those applicants are independently distributed, the planner benefits from a sampling effect. ${ }^{12}$

For public services, which can be divided ex post among several suppliers, ex post competition becomes feasible. The presence of two companies on the same market allows then the planner to draw comparisons from their cost reports, the so-called yardstick competition effect earlier on stressed by Shleifer (1985) and Crémer and McLean (1988).

We now turn to the study of incomplete contracting.

\section{Asymmetric Information and Incomplete Contracting}

In this section, we consider a less ideal environment than that of the previous section. To start with, we list four of the main assumptions that underlie the analysis of comprehensive contracting. For each assumption, we provide a critical discussion of why it is unlikely to be satisfied in many situations. Sections $4.1-4.3$ discuss more thoroughly the consequences of the nonrespect of three of these assumptions. Section 4.4 discusses the best way to organize the production of the public good, i.e. the choice between public and private production. As we argue at the beginning of this section, any fruitful discussion of this choice must be undertaken in an incomplete contracting framework.

Assumptions underlying the comprehensive contracting approach are the following:

- Unified view of the government: The government is assumed to be a single body with welfare maximization as its sole objective. In the real world, the political process is more complex and relies on several layers of delegation and the separation of responsibilities among several public bodies. Examples abound and we just quote a few. Spending and resources ministries are often split, and both have an eye on decision-making. Some public goods provided at a local level by local governments only interested in the welfare of local residents have clear externality effects (highway transportation, environmental regulation, etc...) on nearby localities. In this case, the higher levels of government may put constraints on those local policies or induce coordination between jurisdictions. Also, today political decision-makers may launch a public-good program, which commits their successors even far after they have themselves left office. Lastly, there is a fundamental separation between the legislative level of the government which decides the size and composition of the public good, the bureaucratic level which may regulate the productive sector (or even run it in the case of state-owned enterprises) and the management of the firms within this sector. All those separations between different layers of the chain of command are potential

(C) Blackwell Publishing Ltd. 2005 
sources of agency problems, which create loss of control and transaction costs. We study these problems in the next subsection.

- Full Commitment: The benevolent mediator has the ability to commit to a public good policy even if this service extends over several periods. There is no contractual renegotiation whatsoever. Renegotiation, of course, may improve resource allocation ex post as information becomes available. However, renegotiation may also be costly from an ex ante point of view as we will see in section 4.2.

- Collusion: Behind the use of equilibrium concepts like Bayesian-Nash or dominant strategies equilibria, is the implicit assumption that collusive groups do not form to affect the allocation of resources. This is at odds with the received theory of public choice, which precisely argues that groups may form in the very same contexts where the mediator could use the noncooperative behaviour of their members to elicit costlessly private information. In a fully comprehensive contracting framework, the mediator could costlessly prevent the bilateral communication needed to establish these countervailing coalitions. We study the impact of the behaviour of interest groups on the provision of public goods in section 4.3.

- Full verifiability: The comprehensive contracting paradigm assumes that the level of public good can be contracted upon, i.e. that a Court of Justice can be used to verify its concordance with that specified in the contract. In fact, this level may be function of previous ex ante specific investments made by the agents, the government and the firm, and it may be hard to specify its value in advance. Think, as an example, of the case of education, and more specifically, the specific task of running a school, where both the government and the teachers employed in the program have to invest in specialized training or information acquisition. Sometimes, the quality of the public service may be so complex to verify that it cannot be specified in advance for all future contingencies. Then, this quality is chosen ex post through a simple bargaining procedure among involved parties; the shares of the ex post surplus grasped by all parties depend on their status quo payoffs in case the bargaining fails. These status quo payoffs depend in turn on the allocation of ownership rights on the productive assets. As a result, the allocation of rights affects specific investments and the size of the public good provided. We do not develop this topic further in this survey.

\subsection{Political Rights}

We first study the static inefficiencies that arise from the endowment of political rights, before analyzing the dynamic inefficiencies.

\subsubsection{Static Inefficiencies}

In this section, we model the decision-maker as being chosen out of a political process. Clearly, this delegation of power may create a wedge between the objective of the politician and social welfare.

(C) Blackwell Publishing Ltd. 2005 
For instance, agents may be ex ante heterogenous with respect to their probabilities of having a high or a low willingness to pay for the public good. A benevolent decision-maker would thus maximize expected welfare, taking an average of the distribution of tastes; whereas, an elected decision-maker would maximize the preferences of the median within this distribution.

Even if agents have no veto right whatsoever, the political process, because it biases the objective function of the decision-maker away from efficiency, gives political rights to some agents. The exercise of those rights may interfere with efficiency considerations following the same logic as in Section 3. This point was already made in the framework of redistributive policies by Meltzer and Richard (1981) and the following literature. However, these papers have assumed that only linear taxation is available in a world of complete information. Asymmetric information provides deeper foundations to this inefficiency.

To illustrate, suppose that the median within a distribution of heterogenous agents is more likely to have a low valuation for the public good than the average agent. Then, through the political process, agents with a low willingness to pay are overrepresented. As a result, their tax payment to finance the public good diminishes. This hardens the incentive constraint of agents with a high willingness to pay for the good, because they find very tempting to misrepresent their preferences. The same kind of conflict between efficiency and redistribution as the one we analysed with a benevolent decision-maker and agents having a veto right must then be solved. It has been shown by Ledyard and Palfrey (1999) that the optimal mechanism for a biased decision-maker trades off efficiency and redistribution exactly as mentioned above.

It is worth noticing that, as soon as we fall into the realm of second-best analysis, the political process matters quite a lot in defining the allocation and the distribution of utilities in the society. Different institutional arrangements of the political game may give rise to fluctuations in this distribution as has been noticed by Laffont (1999).

The key point here is that asymmetric information on the agents' preferences somewhat convexifies the set of feasible utilities. Random fluctuations (because of uncertain elections) in the identity of the decision-maker proposing the mechanism for public-good provision yields to the agents an average utility far inside the feasible frontier. In these contexts, it may be good to 'tie the hands' of the decision-maker, by for instance, fixing a priori the level of public good and writing it in the Constitution. Those constraints are good ex ante because they may limit the fluctuations in utilities and move average utility up towards the frontier. Unfortunately, these constraints are bad ex post because they limit the use of discretion by the elected decision-maker. This is an instance of the celebrated trade-off between rules and discretion.

\subsubsection{Dynamic Inefficiencies}

What the previous discussion has shown is that the incompleteness of the Constitution combined with the imperfect representativeness of the political process

(C) Blackwell Publishing Ltd. 2005 
create allocative inefficiencies in a framework with asymmetric information where decision-makers live only for one period.

In reality, some public-good programs last more than one period, and decisions made today on the size of public spending affect the State budget constraint not only today but also in the future. Today's decision-maker may thus put some constraint on his followers by manipulating the level of public spending it leaves to them. We have regrouped the literature addressing this kind of inefficiencies in three groups of models: the random partisan politics models, the tactical redistribution models and the legislative bargaining models.

(a) Random Partisan Politics. A first group of papers having studied dynamic political inefficiencies can be found in the literature on public debt initiated by Persson and Svensson, (1989) and Alesina and Tabellini (1990). These papers have developed complete information models of partisan politics, where two competing parties may alternate in power. A key assumption is that those parties differ with respect to the kind of public goods they would like to see produced. For instance, a leftist government may prefer to spend money on public education, whereas a rightist one is more concerned with defense or urban safety. Also, the identity of the election winner is exogenously given, i.e. the resolution of political uncertainty is independent of the level of economic variables.

In this context, strategic distortions of the State budget constraint become important tools for current governments to favour their own constituencies against those of future majorities with different objectives. The key insight of this literature is that the current government overspends in the public good it prefers to leave its followers with little cash to finance their own set of public goods. Through this channel, the current government perpetuates its own preferences.

A first criticism of this literature has been made by Aghion and Bolton (1989) who endogenize the political uncertainty. Assuming a priori that the rightist government is a better candidate for reimbursing public debt, they also show that the left may want to reduce public spending below what it would like to do because of the threat of not being reelected.

Another criticism of the Personn-Svensson-Alesina-Tabellini approach lies in the set of instruments available. In their articles, governments are restricted to use distortionary tax instruments. Henceforth, one cannot disentangle whether allocative inefficiency in the provision of public good comes from those restrictions or from more fundamental economic phenomena.

To tackle this issue, Martimort (2001) proposes to look at a larger set of redistributive instruments, the set of nonlinear income taxes. However, the elected government is forced to use second-best taxation policies because of asymmetric information on income like in Mirrlees' (1971) seminal paper. The paper is cast in terms of public debt but its main lessons can easily be extended to the case where taxes cover the cost of producing a public good. Suppose that all agents in society are ex ante alike, that they face the same probability of a high-income shock and

(C) Blackwell Publishing Ltd. 2005 
that they like equally well the (unique) public good provided. Two parties are alternating in office over two periods, and the first party in charge decides on the size of the public good program for two periods. Those parties differ with respect to their redistributive concerns; the leftist government tends to redistribute more to low-income agents. Following Mirrlees (1971), asymmetric information on income shocks implies that the optimal taxation policy trades off productive efficiency and redistribution. Of course, this trade-off is less stringent for a rightist government, which is more concerned with efficiency and less with redistribution.

If a single party is in charge for two periods, a dichotomy result holds under mild assumptions. On the one hand, the size of public spending is the same whatever the redistributive concerns of the party in charge. Moreover, the firstbest level of public good is produced. On the other hand, the income tax is used to redistribute according to the government's preferences.

Let us now suppose that the identity of the government changes with some probability in the second period as a result of new elections. Of course, this second period government is constrained by the initial commitment made by its predecessor. To fix ideas, think about a leftist government moving first. If it overspends and produces a level of public good greater than the first-best, it impoverishes society also at date 2 . To finance this excessive spending, the second-period rightist government must raise taxes and behave more like a leftist party eager to tax the rich. ${ }^{13}$ In a political environment, the uncertainty on who will express his political rights through the political process breaks down the dichotomy between efficiency and redistribution. The level of public spending is strategically manipulated by current governments to favour their own redistributive concerns over those of their successors.

The basic message of all the previous papers is clear. The process of delegating power to elected representatives in a democracy, an inherently incomplete contract, generates some inefficiency. This inefficiency is all the more important that political uncertainty matters. As a result, coalition governments face larger misallocations than majoritarian ones provided this uncertainty is more significant with the former. ${ }^{14}$

(b) Tactical Redistribution. One can think of other political processes than those underlying the models on 'random partisan politics' sketched above. Lizzeri (1999) and Lizzeri and Persico (2001) have analysed models of the so-called tactical redistribution. ${ }^{15}$ In those models, candidates do not transfer resources across individuals to redistribute but to target subsets of voters and gain their votes, a natural objective in a world of political competition. The key feature of this competition is that no pure strategy equilibrium exists. Voters face some redistributive uncertainty linked to the game of political promises. This uncertainty interacts with the incentive of candidates to provide an excessive amount of public good.

Lizzeri (1999) is primarily concerned with debt accumulation, but again the lesson of this paper can easily be transposed to public good provision. He shows that overspending is a way for candidates to better target promises to voters,

(C) Blackwell Publishing Ltd. 2005 
which is necessary in order to win elections. In his setting, two successive elections take place with two candidates. Assume first that candidates cannot commit in the first period to a public good scheme offered in the second period, so that no resource saved for the second period can be targeted to particular voters. But any program containing untargeted measures will lose in elections to another program, which favours a majority at the expense of a (small) minority. Consequently, no candidate has any incentive to save resources for the next period, and both overspend on the public good. More surprisingly, the intuition holds true even when candidates can commit in the first period to a second period program. This is because of the fact that a candidate can only commit for himself and not for his opponent. Because there is an element of uncertainty concerning the second period election, this reintroduces the lack of targetability of any resource left for the second period that is responsible for the strategic advantage of overspending on the public good.

Lizzeri and Persico (2001) deal instead with the trade-off between supplying pork barrel projects targeted towards some groups and providing public goods, which concern society as a whole. Public goods cannot be targeted to groups of voters even if they may yield a higher benefit than pork-barrel projects: there is thus a trade-off between efficiency and targetability. As a result of the political competition, there is an inefficiently low provision of public goods, but this inefficiency depends on the political system. For instance, in a proportional system, the benefits of holding seats are shared between parties proportionally to the number of seats they have won. In a majoritarian regime, we are instead in a winner-takes-all setting, where only the winner benefits from some rewards for votes.

The two systems thus differ with respect to the incentives they provide to the competing politicians as can be easily seen in the following example. Suppose that candidate 1 promises to produce the efficient level of public good. In any political system, he can be defeated by candidate 2 if the latter targets a majority of voters with some redistributive program. The margin by which candidate 1 is defeated matters only for a proportional system. As the public good becomes more valuable, redistributive policies become less attractive in a proportional than in a majoritarian system. As a result, the majoritarian system dominates for very valuable public goods.

(c) Legislative Bargaining. The point made above is that different legislative systems change the incentives of politicians, and thus the size and composition of public-good provision. This idea has been strengthened by other contributions in the field of legislative bargaining. Consider, for instance, a country made of three localities, each of them having to build a local public good. When nationwide taxation is used to finance these public goods, it is well known, at least since Weingast et al. (1981), that we have excessive public spending because of a common pool problem, each locality benefitting totally from its local public good while financing only part of its cost. Baron (1991) and Persson and Tabellini (1999) instead argue that legislative bargaining also changes the composition of public spending. An agenda-setter (picked randomly among the representatives of

(C) Blackwell Publishing Ltd. 2005 
different jurisdictions) chooses to get the approval of those jurisdictions which are the cheapest to convince. Only those jurisdictions that are within this set get a positive level of public good. There is overspending for some jurisdictions and underspending for others.

\subsection{Limited Commitment}

One basic and sometimes hidden assumption behind the derivation of the tradeoff between allocative efficiency and rent extraction is that the planner has the full ability to commit itself over several periods. In reality, contracts are by their very nature incomplete and cannot specify all future contingencies. Moreover, the political mandates of public authorities are often limited in time and run only for a few periods.

In those contexts, short-term contracting and renegotiation are the rule and not the exception. For instance, the concession contracts by which a private contractor manages infrastructures often have a fixed duration and are renegotiated afterwards. We now analyse how the impossibility to write a long-term contract affects the trade-off between efficiency and rent extraction. This effect can take three main forms: the ratchet effect, the hold-up problem and renegotiation.

(a) The Ratchet-Effect. Under short-term contracting, the traditional trade-off between allocative efficiency and rent extraction must account for the imperfect revelation of information that occurs over time. Indeed, if information on cost efficiency would be fully revealed earlier on in the relationship between the public authority and the firm, the public authority could extract all the firm's informational rent later on. Afraid of being expropriated from its information rent, the firm manipulates its cost report at the earlier stages of the relationship so that truthful strategies are no longer optimal. Information is only imperfectly revealed over time. This is the so-called ratchet effect, which has been formally studied by Freixas et al. (1985) and Laffont and Tirole (1993; Chapter 10) among others.

Various patterns of information revelation can be obtained depending on the kind of incentive contracts signed between the State and the productive sector (linear contracts or menus of contracts, for instance). However, a general presumption is that efficient firms hide their types in the earlier periods of the relationship. This means that the inability to commit engenders cost overruns and unnecessary spending.

(b) The Hold-Up Problem. Another related problem in short-term contracting environment is the hold-up phenomenon, which takes place when the firm has to make some specific investment prior to the relationship with the State. If this investment is not protected by some form of long-term contracting, the firm is threatened of being expropriated if the State turns later on to another contractor. As a result, the firm underinvests or may even forgo any investment at all. Again, if those investments improve productive efficiency, short-term contracting triggers cost overruns and may be overspending because it dampens investment.

(C) Blackwell Publishing Ltd. 2005 
The existence of the hold-up problem implies that the renewal of concessions should be biased in favour of the incumbent to secure the investments they make in the first periods of the concession as has been shown in Laffont and Tirole (1993; Chapter 8).

We will see below that this hold-up problem has also some consequences for the ownership pattern of infrastructure.

(c) Renegotiation. Sometimes, the planner may have the possibility to commit, at least over the length of its mandate. However, the long-term optimal contract may fail to be time-consistent.

Indeed, as the relationship with the firm is ongoing, new information becomes available and can be used to improve the rent-efficiency trade-off. Renegotiation may improve efficiency ex post. However, renegotiation also hardens incentives ex ante, as has been shown by Hart and Tirole (1988), Dewatripont (1989) and Laffont and Tirole (1994, Chapter 9) among others.

The exact argument goes as follows. Because some information become available in early periods of the relationship, renegotiation increases allocative efficiency ex post. The trade-off between efficiency and rent extraction is tilted towards the former. However, the firm anticipates this increase in efficiency and hides information early on to get more of the gain from renegotiation under the form of information rent ex post. Information revelation is thus slowed down in the organization. Henceforth, renegotiation puts some constraints on what can be achieved by the planner, who would prefer to be able to commit ex ante.

This commitment is often not feasible. This is particularly true when the government is not on a hard budget constraint. Suppose, for instance, that the firm in charge of providing the public good does not exert a sufficient effort in keeping cost low enough. Then, cost overruns may appear and overcome the initial financing commitment of the State. Ex post, the government has incentives to provide further financing to get the project completed anyway. Of course, this renewed financing weakens the ex ante incentives of the firm for keeping cost low.

One has thus to find various forms of institutional safeguards in order to harden the State budget constraint. In the framework of lending by private financiers, Dewatripont and Maskin (1995) have shown that a decentralized finance market with banks endowed with little capital may help to commit not to refinance projects in which the private sector has not put enough effort. The key idea is that the bank, which provides finance in an initial stage of a project, may not refinance if this bank faces some rationing constraint, which is the case in decentralized markets with lenders endowed with little capital. Later stages of financing have thus to be performed by other banks which are at an informational disadvantage with respect to the first one, which already got some information on the quality of the project. Therefore, those new banks offer credit at a premium. This extra cost of credit hardens the borrower's incentive ex ante.

Transposed in a public-good context, this argument gives some credit to the idea that joint control between the State and local authorities or full decentralization to local governments who have harder budget constraints may help.

(C) Blackwell Publishing Ltd. 2005 
This point has been explored in a regulatory context by Martimort (1999b). The point made in this paper is that multiple regulatory authorities should be involved in the renegotiation of concession contracts. If these authorities have conflicting objectives, the gains from renegotiation ex post may be somewhat dissipated in the bargaining between those parties and the firm. This is the case, in particular, if some frictions because of asymmetric information make impossible Coasian bargaining ex post. In practice, an economic regulator concerned with consumers' surplus and an environmental one preoccupied with the well-being of environmentalists may disagree over the amount of production and polluting damages allowed to the firm at the renegotiation stage. Similarly, a Federal regulator and a local one may not agree over the size of a project undertaken at the local level if the latter exerts an externality on other jurisdictions. Such ex post conflicts make more credible that renegotiation will be costly ex post. As a result incentives of the firm are exacerbated from an ex ante point of view.

An open question is to determine the degree of ex post conflict needed to improve commitment ex ante. It may also be hard to generate conflict ex post at the renegotiation stage without also generating conflict, earlier on, at the negotiation stage. Of course, this latter form of conflict is costly for public decision-making. Olsen and Torsvick (1991) show that there is an optimal interior number of public authorities which should be involved. This number trades off the benefits of increasing conflict ex post, which is good from an intertemporal welfare viewpoint, with the costs of increasing conflict ex ante.

Another quite unsettled question concerns the design of the objective functions of the various public authorities involved. Tirole (1994) makes some progress towards solving this problem. In incomplete contracting environments, parties to the contract may not have the ability to write ex ante who should intervene in the course of actions, as some nonverifiable signals on the action of the firm become available. The precise design of the objective functions of the public authorities involved, in other words their incentive schemes, helps to give those parties the right incentives to intervene ex post. As an example, think about a long-term project being undertaken by a private contractor. In the course of action, some signal correlated with the firm's effort, and the final cost of the project may become available. Conditionally, on this signal, an action should be undertaken by the State: either to stop the project early or to refinance it. In hard times, bad signals over the performances of the firm become available, and a tough Ministry of Finance concerned with the viability of the project should intervene to stop the project. Instead, in good times, good signals are available, and a soft Ministry of Industry concerned with the long-run profit of the industry should recommend the continuation of the project.

\subsection{The Behaviour of Interest Groups}

In this section, we relax another basic assumption underlying the use of the Revelation Principle, i.e. the fact that agents do not form coalitions of interests 
to promote their own objectives. Indeed, large organizations and, more generally, societies as a whole are characterized by the formation of such groups between agents who share common economic interests or the same sociological characteristics. The formation of groups in the political arena may put further constraints on the optimal policy for public-good provision and somewhat affect the lessons of section 3 .

In what follows, we analyse in turn group formation on the demand and on the supply sides because they lead to quite different modifications of the trade-off between efficiency and rent extraction.

\subsubsection{Group Formation on the Demand Side}

The free-rider problem in public-good provision is highly dependent on the assumption that agents are selfish maximizers of their well-being under asymmetric information. To avoid this problem and get more positive results, coalition formation may be a solution if it destroys the informational asymmetry among its members. To understand the issue at stake, the framework of Dequiedt and Martimort (2004), even if it is not directly related to a public-good problem, may be useful.

The key problem in this paper is to investigate whether the planner should let a coalition form or not. To form a strong coalition, agents must share information, and learning each others' types entails a fixed cost of information gathering. This fixed cost can be viewed as the cost of collective action in the vocabulary of Olson (1965). Moreover, the mere fact of learning is nonverifiable by the planner who must thus also solve a moral hazard problem. The benefits of having agents learning each others' types is to prevent free-riding from occurring at least within the group. Out of this trade-off emerges an optimal size of the interest group intervening in the public area.

What is striking is that the moral hazard problem creates a nonconvexity in the planner's problem. Small modifications of the cost of information gathering lead to significant discontinuous jumps in the amount of public good provided. When these costs are small enough, the public good is significantly closer to efficiency. Group formation helps on the demand side.

Laffont and Martimort (1999a) instead look at the case of a weak coalition, where colluding agents cannot credibly share information on their preferences. They must thus build an incentive-compatible mechanism to share the benefits of colluding. If the planner is unrestricted in his tax instruments, the threat of coalition formation does not affect the optimal mechanisms if types are independently distributed. If the planner is instead restricted to offer anonymous mechanisms, coalition formation may move the policy towards a third-best outcome with even less public good being produced than with a selfish behaviour on the agents' side. Group formation, in this case, is bad.

\subsubsection{Capture on the Supply Side}

There is a fundamental separation between the legislative layer of the government which defends the interests of voters and its administrative branch, the regulatory

(C) Blackwell Publishing Ltd. 2005 
agencies in charge of the day-to-day control and the monitoring of the regulated industry supplying the public good.

It is well known ${ }^{16}$ that bureaucrats may fall under the influence of the industry they are supposed to regulate. Regulators are supposed to bridge the informational gap between uninformed policy maker and the privately informed industry. The mere fact that they share some information with the industry opens up the possibility of strategic manipulations of this information to promote the industry interest in exchange of some bribes that may take the form of in-kind favours as well as the perspective of future employment opportunities in the industry (revolving doors).

This threat of capture is harmful for policy making. The regulator, through his informational advantage, has some discretion over the regulatory mandate. The optimal regulatory response to capture is then to reduce this discretion as it has been shown by Laffont and Tirole (1993; Chapter 11). This means that the tradeoff between rent extraction and allocative efficiency is tilted even further away from efficiency. Alternatively, everything happens as if the cost of capture raised the cost of public funds.

More specifically, it is interesting to understand which institutional responses to the threat of capture may complement this simple reduction of the regulator's discretion and move public decision-making towards more efficient outcomes. Laffont and Martimort (1999b) show that some degree of informational separation between various regulatory authorities in control of the firm helps to reduce the overall cost of capture. Martimort (1999a) explicitly endogenizes the frictions of collusive contracting between the regulator and the firm by modelling the repeated game between these agents. He shows that the institutional framework affects the transaction costs of side-contracting and thus how efficient the regulation of the firm is. For instance, both the separation of regulators (i.e. a limit on the scope of their power) and the shortening of the duration of their holding office, help in increasing transaction costs. The kind of norms for collusive behaviour established in society also plays an important role. Large scale policies against corruption and commitments by high-level public authorities to fight those practices may help changing the trajectory of the economy and make the self-enforcing capture between regulators and firms harder to establish.

\subsection{Ownership Patterns}

The important question left unanswered so far is the following: what sorts of public goods should be provided by public enterprises as opposed to private firms? Governments use their own employees to perform some services like police, defense, education, whereas other services, like garbage collection, are contracted out to the private sector.

To understand the proper scope for government, we should first realize that the framework of fully comprehensive contracting is unable to provide us with an answer. Indeed, ownership patterns do not matter in this environment: the government, modelled as a benevolent mediator, can give the same incentives to

(C) Blackwell Publishing Ltd. 2005 
the private and the public sectors at the same cost. Note that this result is true even if this cost takes into account the informational constraints already stressed by this survey. For the private sector, this can be done by regulation whereas direct control plays this role for public enterprises.

The key difference in ownership patterns comes instead from the residual rights of control that an owner of an asset exerts when unforeseen contingencies arise. In such instances, ownership gives the owner the right to use the assets as one prefers. More precisely, the owner cannot refrain from using the asset in the best available use from one's point of view. This is what has been called the phenomenon of selective intervention by Williamson (1985) and Sappington and Stiglitz (1987).

We present hereunder three ways the economic literature has studied ownership patterns: by seeing privatization as a commitment device, by looking at the specificities of incentives in the public sector, and by analysing the trade-off between cost reduction and quality innovation.

\subsubsection{Privatization as a Commitment Device}

The point made by Sappington and Stiglitz (1987) is that the government cannot commit itself not to intervene in the control of the public enterprise, whereas such commitment becomes possible if assets have been sold to private entrepreneurs because, for instance, enacting a new regulation takes time and is costly. Privatization, even though it is accompanied by some regulation, acts thus as a commitment device not to interfere with the day-to-day control of the firm.

However, it is not completely clear that privatization alone achieves this goal. Think, for example, of a network industry (telecommunication, rail, water industry or electricity) where large capital investments must be made and suppose that, because of strong pressures on cutting public spending, the government has decided to privatize this natural monopoly. Of course, for outside investors to be willing to invest into those new projects, the firm must recoup some of its investments under the form of some positive cost-price margin. Once the capital has been sunk, the risk is that the government, as a defender of consumers, will regulate price and reduce the rate-of-return on the investment. Outside investors may thus choose to reduce the initial investment or, even worse, to forego any such investment. The threat of a regulatory hold-up puts a bound on the size of the investment.

However, as has been noticed by Gilbert and Newbery (1993), a repeated relationship between the State and the firm may, at least partially, solve this problem. When the regulation game is repeated, the State refrains from imposing a tough regulation on the firm from fear that investors stop renewing its capital stock. At the same time, investors renew capital because they expect a proconsumers regulation if they stop doing so. An equilibrium with so-called trigger strategies (i.e. a return to the opportunistic behaviour forever if anyone deviates from the equilibrium behaviour) sustains an efficient investment if parties put enough value on the future of their relationship.

(C) Blackwell Publishing Ltd. 2005 
The solution to the hold-up problem thus involves not only privatization but also a credible regulation. This shows that the private sector can always do as well as the public sector if the regulatory environment sticks to the right nonopportunistic behaviour. However, this does not show that the private sector can do better.

Riordan (1990) and Schmidt (1996) have proposed incomplete contract models which try to pin down a unique advantage of a privatized sector. In those models, ownership of an asset gives the owner access to information relevant for the use of this asset. Suppose that the State owns the assets needed to produce the public good and knows accordingly whether the asset is efficient or not. An efficient asset allows to produce at a low marginal cost while an inefficient one increases this cost. The key insight of those papers is that, by relinquishing ownership to the private sector, the State commits itself to leave some informational rent to the firm, at least when it is efficient. This rent boosts ex ante incentives to make specific investment in the assets and partially solves the hold-up problem. Under public ownership, promises to reward the firm's investments are not credible. Once the efficiency of the asset is known, the State would like the firm to produce at marginal cost and suppress any rent, destroying thereby also ex ante incentives to invest.

In these papers, outside investors have a quite obscure role. The firm, when it is privatized, is a manager-owned enterprise, or differently stated, private owners have enough cash to start the venture on their own without relying on the capital market. Laffont and Tirole (1993; Chapter 17) have introduced explicitly the separation between financiers and managers of the private venture and shown that a new contractual externality enters the picture. The benefits of private ownership is still that it secures specific investments. The cost, however, is that the manager has now to respond to two masters: on the one hand, the State as a regulator and a defender of consumers; on the other hand, shareholders or other financiers who want to get some financial returns from their initial investment. The consequence of this multiprincipal externality is that there is an excessive rent extraction by the two principals who do not coordinate themselves in designing the management incentives. The trade-off between rent extraction and efficiency is definitely tilted away from efficiency.

\subsubsection{Incentives in the Private and the Public Sector}

Political scientists have long argued on the specificities of incentives in the public sector. The most definitive account of these issues is probably given by Wilson (1989). This author has shown that what distinguishes a civil servant from an employee of a private bureaucracy is the fuzziness of its missions, or more technically speaking, the fact that, in the public sector, bureaucrats respond to various principals having sometimes conflicting interests: the Congress, or more precisely, several Committees in Congress, the various interest groups concerned by the bureaucrat's decisions, etc.

(C) Blackwell Publishing Ltd. 2005 
Dixit (1997) has proposed some modelling of these multiprincipal externalities in a moral hazard environment where the agents' efforts, or array of tasks, cannot be directly controlled by the various principals interested in public decisionmaking. The main result of the analysis is probably that the bureaucrat receives, in equilibrium, some excessively low-powered incentives.

Everything happens as if, as a result of these multiple supervisors, the bureaucrat was systematically biased towards the status quo. In practice, this means that efficiency in the public sector is unlikely to be obtained.

A weakness of the analysis comes from the fact that the same multiple influences also put pressures on the manager of the private firms, and it is not clear why the multiprincipal externality should be, in any sense, harder within the public sector. There is some presumption but not a definitive proof that public bureaucracies are less efficient than their private counterparts.

The same kind of comments has also been done with respect to capture. For Newbery (1992), the key difference between the public and the private sector is that the former has a comparative advantage in capturing the regulatory institutions. The British experience in privatizing and regulating utilities can be reminded here. Under public ownership, utilities were forced to earn a specified rate of return on their investments and did so by raising prices sufficiently. After privatization, a new price cap regime was adopted with the requirement of identifying clearly profit lines and losses. This more efficient mode of regulation was not adopted during the 40 years of public ownership, and this fact appears as an evidence of a more pronounced capture in public ownership.

Shapiro and Willig (1990) start from this basic premise that regulators are somewhat biased to protect the interest of the public enterprise they control. They argue that privatization helps to short-cut this inefficient layer of the regulatory hierarchy. The associated cost is that privatized firms' managers obey shareholders who have their own objectives differing from social welfare.

The comparison between the scope for capture in the private and in the public sectors seems to us a fascinating route to explore but until now, all models seem to be biased a priori against public ownership.

\subsubsection{The Trade-Off between Cost Reduction and Quality Innovation}

Hart et al. (1997) have proposed a model discussing the pros and cons of privatization when both cost reduction and quality innovation are looked after by the government. The starting observation is that proponents of state ownership often argue that the pressure for cost reduction in the private sector swamps any incentives to improve quality. In the framework proposed by theses authors, neither cost nor quality can be contracted upon ex ante, but each time there is a possible innovation on either of these dimensions, the innovating agent needs the approval of the owner to implement his ideas. Efforts in cost reduction and quality innovation are substitutes in the sense that a cost reduction decreases quality. 
In the public sector, the agent has typically too few incentives to reduce cost and improve quality because he does not own the asset and needs the government's approval to do so. Under private ownership, the agent does not need the government's approval to reduce cost, whereas one needs it for quality innovation because the government ultimately buys the service. Henceforth, the agent engages in excessive cost reduction and this spills over onto his incentives to provide quality which are de facto depressed. ${ }^{17}$

Private ownership leads to excessive incentives to invest in cost reduction and to moderate incentives to improve quality. Private ownership is unambiguously superior to public ownership when the deterioration of quality for cost reduction is small. Public ownership is instead dominating when this deterioration is large or quality innovation important.

\section{Summary}

This survey starts with the benchmark complete information case, where the planner has all relevant information on costs and preferences and where transaction costs are absent. The optimal amount of public good is given by the Samuelson condition that equates the marginal cost of the public good (i.e. the cost of providing one more unit of the good to all consumers) and the sum of the marginal willingnesses to pay for it. In such a perfect world, there is no conflict between efficiency and redistributive concerns. Moreover, the initial distribution of rights among agents (consumers and producers) does not play any significant role.

The bulk of this survey is devoted to the study of public good provision in presence of asymmetry of information, i.e. when the planner does not know with certainty the production technology of firms and the preferences of each member of society. We first review the comprehensive contracting literature, where the benevolent, welfare-maximizing planner can contract on anything that is observable, including the public good level. Trade-offs appear both on the demand and on the supply side of the economy.

On the demand side of the economy, the main trade-off is between efficiency and minimum rights. Various authors have pointed out that it is possible to find allocation rules that ensure both efficiency (i.e. the optimal, first best, amount of the public good is produced) and budget balance (the sum of individual contributions is equal to the total cost of producing the good). Unfortunately, such mechanisms fail to ensure a minimum level of welfare to all individuals, and especially to those with the lowest valuations for the public good. The literature has studied three ways to react to this trade-off. The first one is to modify the structure of rights to benefit efficiency. The second one is to opt for a (efficient) mechanism which minimizes violations of the minimal rights. The last possibility is to minimize the inefficiency of the public good provision while respecting all basic rights. This last approach leads to a modified Samuelson rule obtained by dividing the true willingnesses to pay by the shadow cost of public funds (i.e. the measure of the deadweight loss of taxation). This results in a lower than (first 
best) optimal amount of public good, which may even tend towards zero for large public goods.

On the supply side, the basic trade-off is efficiency versus rent extraction. The planner has to leave a (informational) rent to the most cost-effective producers to prevent them from mimicking less efficient ones. This leads to a new modification of the Samuelson optimality condition, where the sum of individual valuations is compared to an inflated marginal cost. This, of course, results in a lower than otherwise optimal quantity of public good, the distortion increasing with the shadow cost of public funds (which makes the informational rent very costly in welfare terms). To alleviate this problem, the planner should organize ex ante competition (i.e. competition for the market when competition in the market is unreasonable), coupled with yardstick competition (i.e. comparison of performances of similarly positioned public good providers) wherever possible (e.g. in the case of local public goods, where different providers are active in different jusrisdictions).

The complete contracting approach is based on three very demanding assumptions: a unified view of government, the ability for this government to fully commit to a policy and the absence of any collusion in the economy. The failure to satisfy any of these assumptions gives rise to a particular form of incomplete contracting that we study in turn.

We first focus on the consequence for contractual incompleteness of having an elected policy maker. This gives rise to two sources of static inefficiencies. First, the decision maker must take into account the political rights of its constituents, which results in an efficiency/redistribution trade-off. At its simplest, this trade-off results in the policy maker catering no longer to the average preference in the economy, but rather to the median preference in order to be reelected. A second static tradeoff that emerges with an elected policy maker is the 'rules versus discretion' one. Individuals generally suffer from the uncertainty linked to election results. This would call for tying the hands of the decision maker by designing general rules to be followed by any election winner. On the other hand, general rules limit the ability of the policy maker to adapt to unforeseen circumstances, thus calling for some discretion.

Dynamic inefficiencies arise when current decisions are used to put constraints on the next election's winner. A first strand of literature, called random partisan politics, stresses that this behaviour generates all the more inefficiencies that political uncertainty is important. The literature on tactical redistribution focuses on the need to target resources to particular voters in order to win elections. The inability to commit to a policy after the elections, because of political uncertainty, leads to too much targeting in the pre-election period. This efficiency/targetability trade-off results in distortions in both the public good's quantity (too much is produced) and composition (which is biased towards pork-barrel projects, i.e. projects that only benefit a targeted minority). Furthermore, the political system used (e.g. proportional or majoritarian) affects the incentives to current decision makers. The literature on legislative bargaining also gives similar results. 
The impossibility of writing long-term contracts (limited commitment) affects the trade-off between efficiency and rent extraction in various ways. First, if the decision maker cannot commit not to use any information revealed over time to reduce informational rents, efficient firms will be reluctant to identify themselves as such early on in the relationship. This so-called ratchet-effect will then lead to cost overruns. A related problem lies in the effects of renegotiation. While renegotiation increases allocative efficiency ex post, firms anticipate them and are tempted to let cost overruns happen in the belief that the government will anyway provide the additional funding needed through renegotiation. To counteract this detrimental ex ante effect of renegotiation, the decision maker should render renegotiation more costly ex post. One way to do this is to give joint control of renegotiation to several entities (such as levels of governments, ministries or regulators) whose objectives differ. Finally, in the case where the firm has to make some specific investment, the renewal of concessions should be biased in favour of the incumbent to give it incentives to do the required investment without having to fear a hold-up situation.

Allowing agents to form coalitions to promote their objectives affects the basic trade-offs both in the demand and the supply sides. On the demand side, the result depends very much on whether group members can credibly share information on their preferences. If they can, group formation helps to get closer to efficiency because it prevents free-riding from occurring within groups. If not, group formation further decreases efficiency. On the supply side, coalition formation means threat of capture of bureaucrats/regulators by the industry they are supposed to overview. Such threats may be alleviated by reducing the regulators' discretion, separating from an informational viewpoint the various regulatory authorities or modifying the length of their holding office.

Finally, the optimal way to provide public goods (i.e. the choice between public and private providers) can only be studied in an incomplete contracting framework, because comprehensive contracting allows to give the same incentives to both kinds of firms. The literature has studied ownership patterns in three ways. The first states that privatization, together with a credible regulation, acts as a commitment device. The advantage of privatization in this approach is that, by leaving an informational rent to efficient firms, it improves their incentives to make specific investments. Another branch of the literature claims that the public sector is plagued with multiprincipals externalities (due, for instance, to the fuzziness of the public sector's missions) which result in excessively low powered incentives. On the other hand, it is not clear why the private sector does not suffer from the same multiplicity of influences (due, for instance, to the separation between managers and financiers). Existing models thus seem biased a priori against public ownership. Third, the literature has also studied the trade-off between cost reduction and quality improvement and concluded that private ownership leads to excessive incentives to invest in cost reduction and to moderate incentives to improve quality. Private ownership is unambiguously superior to public ownership when the deterioration of quality for cost reduction is small.

(C) Blackwell Publishing Ltd. 2005 


\section{Notes}

1. Sometimes, the public good is a $0-1$ decision like building a bridge or a new university. The logic of the previous condition applies but in discrete incremental terms of course. The project is performed if the sum of the agents' valuations exceeds the fixed cost of the project.

2. The quasi-linearity assumption will be kept all along the paper.

3. That is, the utility they get when they refuse to enter the game. This utility is often normalized to zero.

4. Except under rare circumstances detailed in Makowski and Mezetti (1994).

5. Of course, ex ante, everybody has an equal chance of being in the sample.

6. For recent contributions along these lines, see Moldovanu (2001) and Fieseler et al. (2001).

7. See Laffont and Martimort (1999a) and Laffont and Martimort (2005) for such a second-best policy in the case of infrastructure in developing countries.

8. The cost of public funds measures the extra cost for the economy of using one additional euro of public spending out of the State's budget. It arises because distortionary taxation is needed to finance the State's budget.

9. At least in the case of a binary decision.

10. See Baron and Myerson (1982) and Laffont and Tirole (1993) among others.

11. See, for instance, Laffont and Tirole (1993, Chapter 7).

12. See Auriol and Laffont (1992), Dana and Spier (1994) and Lee and Hamilton (1999).

13. Of course, the reverse happens had a rightist government been elected first.

14. See Alesina and Roubini (1992).

15. This expression was coined earlier on by Dixit and Londregan (1998). See also Myerson's (1993) seminal paper.

16. See Wilson (1989), for instance.

17. This idea is reminiscent of the multitask problem analysed by Holmstrom and Milgrom (1991). However, the latter is developed in a comprehensive contracting framework with moral hazard.

\section{References}

Aghion, P. and Bolton (1989). Government domestic debt and the risk of default. In R. Dornbush and M. Draghi (eds), Capital Markets and Debt Management. London: Cambridge University Press.

Alesina, A. and Roubini, N. (1992). Political cycles in OECD economies. Review of Economic Studies 59: 663-688.

Alesina, A. and Tabellini, G. (1990). a positive theory of fiscal deficits and government debt. Review of Economic Studies 57: 403-415.

Arrow, K. (1979). The property rights doctrine and demand revelation under incomplete information. In M. Boskin (ed.), Economics and Human Wealth. New York: Academic Press.

d'Aspremont, C. and Gérard-Varet, L. A. (1979). Incentives and incomplete information. Journal of Public Economics 11: 25-45.

Auriol, E. and Laffont, J. J. (1992). Regulation by Duopoly. Journal of Economics and Management Strategy 1: 507-533.

Baron, D. (1991). Majoritarian incentives, pork barrel programs and procedure control. American Journal of Political Sciences 35: 57-90. 
Baron, D. and Myerson, R. (1982). Regulating a monopolist with unknowns costs. Econometrica 50: 911-930.

Cramton, P., Gibbons, R. and Klemperer, P. (1987). Dissolving a partnership efficiently. Econometrica 55: 615-632.

Crémer, J. and McLean, R. P. (1988). Full extraction of the surplus in bayesian and dominant strategy auctions. Econometrica 56: 1247-1257.

Dana, J. and Spier, K. (1994). Designing a private industry: Government auctions with endogenous market structures. Journal of Public Economics 53: 127-147.

Dequiedt, V. and Martimort, D. (2004). Delegated monitoring versus arm's length contracting. International Journal of Industrial Organization, 22: 951-981.

Dewatripont, M. (1989). Renegotiation and information revelation over time: The case of optimal labor contracts. Quarterly Journal of Economics 104: 589-618.

Dewatripont, M. and Maskin, E. (1995). Credit and efficiency in centralized and decentralized economies. Review of Economic Studies 62: 541-555.

Dixit, A. (1997).The Making of Economic Policy. Cambridge, MA: MIT Press.

Dixit, A. and Londregan, J. (1998). Ideology, tactics, and efficiency in redistributive politics. Quarterly Journal of Economics 113: 497-529.

Fieseler, K., Kittsteiner, T. and Moldovanu, B. (2001). Partnerships, lemmons and efficient trade. Mimeo: U. Mannheim.

Freixas, X., Guesnerie, R. and Tirole, J. (1985). Planning under incomplete information and the ratchet effect. Review of Economic Studies 52: 173-192.

Gary-Bobo, R. and Jaaidane, T. (2000). Polling mechanisms and the demand revelation problem. Journal of Public Economics 76: 203-238.

Gilbert, R. and Newbery, D. (1993). The dynamic efficiency of regulatory constitutions. Rand Journal of Economics 25: 538-554.

Green, J. and Laffont, J. J. (1979). Incentives in Public Decision-Making. Amsterdam: North-Holland.

Groves, T. (1973). Incentives in teams. Econometrica 41: 617-631.

Hart, O., Shleifer, A. and Vishny, R. (1997). The proper scope of government: Theory and application to persons. Quarterly Journal of Economics 112: 1091-1126.

Hart, O. and Tirole, J. (1988). Contract renegotiation and coasian dynamics. Review of Economic Studies 55: 509-540.

Holmstrom, B. and Milgrom, P. (1991). Multi-task principal-agent analysis: Incentive contracts, asset ownership and job design. Journal of Law, Economics and Organization 7: 24-52.

Laffont, J. J. (1999). Incentives and Political Economy. Oxford: Oxford University Press.

Laffont, J. J. and Martimort, D. (1999a). The collusion-proof samuelson conditions for public good. Journal of Public Economic Theory 1: 399-438.

Laffont, J. J. and Martimort, D. (1999b). Separation of regulators against collusive behavior. Rand Journal of Economics 65: 627-630.

Laffont, J. J. and Martimort, D. (2002). The Theory of Incentives: the Principal-Agent Model. Princeton: Princeton University Press.

Laffont, J. J. and Martimort, D. (2005). The design of transnational decision mechanisms for infrastructures in developing countries. Journal of Public Economics, 89: 159-196.

Laffont, J. J. and Maskin, E. (1979). On the difficulty of attaining distributional goals with imperfect information about consumers. Scandinavian Journal of Economics 81 (2): $227-237$.

Laffont, J. J. and Tirole, J. (1993). A Theory of Incentives in Procurement and Regulations. Cambridge: MIT Press.

Ledyard, J. and Palfrey, T. (1999). A characterization of interim efficiency with public goods. Econometrica 67: 435-448.

Lee, S. and Hamilton, J. (1999). Using market structure to regulate a vertically integrated monopolist. Journal of Regulatory Economics 15: 213-248.

(C) Blackwell Publishing Ltd. 2005 
Lizzeri, A. (1999). Budget deficits and redistributive politics. Review of Economic Studies 6 (909): 928.

Lizzeri, A. and Persico, N. (2001). The provision of public goods under alternative electoral incentives. American Economic Review 91: 225-239.

Mailath, G. and Postlewaite, A. (1990). Asymmetric information bargaining problem with many agents. Review of Economic Studies 57: 351-367.

Makowski, L. and Mezetti, C. (1994). Bayesian and weakly robust first-best mechasnisms: Characterizations. Journal of Economic Theory 64: 500-519.

Martimort, D. (1999a). The life cycle of regulatory agencies: Dynamic capture and transaction costs. Review of Economic Studies 66: 929-947.

Martimort, D. (1999b). Renegotiation with multiple regulators. Journal of Economic Theory 88: 269-294.

Martimort, D. (2001). Optimal taxation and strategic budget deficit under political regime switching. Review of Economic Studies 68: 573-592.

Meltzer, A. and Richard, S. (1981). A rational theory of the size of government. Journal of Political Economy 89: 914-927.

Mirrlees, J. (1971). An exploration in the theory of optimum income taxation. Review of Economic Studies 38: 175-208.

Moldovanu, B. (2001). How to dissolve a partnership. Mimeo: U. Mannheim.

Myerson, R. (1979). Incentive compatibility and the bargaining problem. Econometrica 47: $61-73$.

Myerson, R. (1993). Incentives to cultivate favored minorities under alternative electoral systems. American Political Science Review 87: 856-869.

Neeman, Z. (1999). Property rights and efficiency of voluntary bargaining under asymmetric information. Review of Economic Studies 66: 679-691.

Newbery, D. (1992). The role of public enterprises in the national economy. Washington: IPR45.

Olsen, T. and Torsvick, G. (1991). The ratchet effect in common agency: Implications for regulation and privatization. Journal of Law, Economics and Organization 91: $136-158$.

Olson, M. (1965). The logic of collective action: Public goods and the theory of groups. Cambridge, MA: Harvard University Press.

Persson, T. and Svensson, L. (1989). Why a stubborn conservative would run a deficit: Policy with time-inconsistent preferences. Quarterly Journal of Economics 104: 325-345.

Persson, T. and Tabellini, G. (1999). The size and scope of government: Comparative politics with rational politicians. European Economic Review 43: 699-735.

Riordan, M. (1990). What is vertical integration. In M. Aoki, B. Gustaffron and O. Williamson (eds), The Firm as a Nexus of Treaties. London: European Sage.

Rob, R. (1989). Pollution claim settlements under private information. Journal of Economic Theory 47: 307-333.

Samuelson, P. (1954). The pure theory of public expenditure. Review of Economics and Statistics 36 (4): $387-389$.

Samuelson, W. (1985). A comment on the coase theorem. In A.E. Roth (ed.), Game Theoretic Models of Bargaining. Cambridge: Cambridge University Press.

Sappington, D. and Stiglitz, J. (1987). Privatization, information and incentives. NBER no. 2196.

Schmidt, K. (1996). the cost of benefits of privatization: An incomplete contract approach. Journal of Laws, Economics and Organization 12: 1-24.

Shapiro, C. and Willig, R. (1990). Economic rationales for the scope of privatization. John M. Olin Program for the Study of Economic Organization and Public Policy: 41.

Shleifer, A. (1985). A theory of yardstick competition. Rand Journal of Economics 16: 319-327. 
Tirole, J. (1994). The internal organization of the government. Oxford Economic Papers 46: $1-29$.

Weingast, B., Shepsle, K. and Johnsen, C. (1981). The political economy of benefits and costs: A neoclassical approach to distributive politics. Journal of Political Economy 89: 642-664.

Williamson, O. (1985). The Economic Institutions of Capitalism. New York: Free Press.

Wilson, J. (1989). What Bureaucracies Do and Why They Do It. New York: Basic Books. 